\title{
Nurse-initiated, titrated intravenous opioid analgesia reduces time to analgesia for selected painful conditions
}

\author{
Anne-Maree Kelly, MD, MClinEd, FACEM; ${ }^{*}$ Catherine Brumby; ${ }^{\dagger}$ Caroline Barnes, $\mathrm{BN}^{\ddagger}$
}

\begin{abstract}
Objectives: Traditionally, patients have to wait until assessed by a physician for opioid analgesia to be administered, which contributes to delays to analgesia. Western Hospital developed a protocol enabling nurses to initiate opioid analgesia prior to medical assessment for selected conditions. The aim of this study was to determine the impact of this protocol on time to first opioid dose in patients presenting to the emergency department (ED) with renal or biliary colic.

Methods: This was an explicit medical record review of all adult patients with an ED discharge diagnosis of renal or biliary colic presenting to a metropolitan teaching hospital ED. Patients were identified via the ED data management system. Data collected included demographics, condition, triage category, time of presentation, whether analgesia was nurse-initiated or not, and interval from arrival to first opioid analgesic dose. The narcotic drug register for the relevant period was also searched to cross-check whether opiates were doctor- or nurse-initiated.

Results: There were 58 presentations in the nurse-initiated opioid analgesia group and 99 in the non-nurse-initiated analgesia group. Groups were reasonably well matched for gender, triage category and time of presentation, but there was a higher proportion of biliary colic in the non-nurse-initiated analgesia group. Median time to first analgesic dose was 31 minutes in the nurse-initiated group and 57 minutes in the non-nurse-initiated analgesia group (effect size, 26 minutes; $95 \%$ confidence interval $16-36 \mathrm{~min} ; p<0.0001]$. There were no major adverse events in either group.

Conclusion: A nurse-initiated opioid analgesia protocol reduces delays to opioid analgesia for patients with renal and biliary colic.
\end{abstract}

Key words: emergency department; analgesia, nurse-initiated

\section{RÉSUMÉ}

Objectifs : Traditionnellement, les patients devaient attendre d'avoir été évalués par un médecin avant de recevoir une analgésie aux opiacés, ce qui contribuait à des délais avant l'analgésie. Le Western Hospital a mis sur pied un protocole autorisant les infirmières à commencer une anal-

\footnotetext{
*Professor and Director, Joseph Epstein Centre for Emergency Medicine Research, Western Hospital, Melbourne, Victoria, Australia; and Department of Medicine, The University of Melbourne, Melbourne, Victoria

tMedical Student, Advanced Medical Science Program, The University of Melbourne, Melbourne

¥Clinical Nurse Consultant, Department of Emergency Medicine, Western Hospital, Melbourne
}

This work was undertaken as part of the Advanced Medical Science Program of The University of Melbourne, Melbourne, Victoria, Australia.

Received: June 27, 2004; final submission: Jan. 18, 2005; accepted: Jan. 31, 2005

This article has been peer reviewed.

Can J Emerg Med 2005;7(3):149-54 
gésie aux opiacés avant l'évaluation par le médecin pour certaines atteintes. La présente étude avait pour objectif de déterminer l'impact de ce protocole sur le délai avant l'administration de la première dose d'opiacés chez des patients reçus au département d'urgence (DU) pour une colique néphrétique ou biliaire.

Méthodes: II s'agit d'une revue explicite des dossiers médicaux de tous les patients adultes du département d'urgence d'un hôpital universitaire métropolitain dont le diagnostic lors de leur congé était une colique néphrétique ou biliaire. Les patients furent identifiés grâce au système de gestion des données du DU. Les données recueillies comprenaient les données démographiques, l'état du patient, la catégorie de triage, l'heure de présentation, la mise en marche de l'analgésie par l'infirmière ou non, et l'intervalle entre l'arrivée à l'urgence et la première dose d'analgésique opiacé. Le registre des médicaments narcotiques pour la période pertinente fut aussi consulté afin de procéder à une contre-vérification à savoir si les opiacés avaient été administrés par le médecin ou par l'infirmière.

Résultats: Il y avait 58 cas dans le groupe chez qui l'analgésie avait été commencée par une infirmière et 99 cas dans le groupe chez qui l'analgésie n'avait pas été commencée par une infirmière. Les groupes étaient raisonnablement bien appariés quant au sexe, à la catégorie de triage, à I'heure de présentation, mais il y avait une proportion plus importante de cas de colique biliaire dans le groupe dont l'analgésie n'avait pas été commencée par une infirmière. Le délai médian jusqu'à la première dose d'analgésique était de 31 minutes pour le groupe dont l'analgésie avait été commencée par une infirmière, et de 57 minutes pour le groupe dont l'analgésie n'avait pas été commencée par une infirmière (ampleur de l'effet, 26 minutes; intervalle de confiance de 95\% 16-36 min; $p<0,0001$ ). II n'y eut aucun événement indésirable dans l'un ou l'autre des groupes. Conclusion: Un protocole d'analgésie aux opiacés commencée par une infirmière réduit le délai jusqu'à l'analgésie chez les patients atteints de colique néphrétique ou biliaire.

\section{Introduction}

Inadequate management of acute pain in the emergency department $(\mathrm{ED})$ is an internationally recognized problem. ${ }^{1-6}$ This is of particular concern given that pain is the most common presenting complaint to the ED..$^{7-9}$ In order to improve analgesia delivery, the Department of Emergency Medicine at Western Hospital has been developing and implementing pain management policies since 1995. In 1995, a nurse-managed, titrated intravenous (IV) analgesia protocol was implemented. The decision to provide opioid analgesia was the responsibility of physicians, but ongoing pain management, including titration of subsequent doses of narcotic, was the responsibility of appropriately trained nurses. Key components of the protocol were a change from intramuscular to IV dosing, frequent pain severity reassessment, and the empowerment of nursing staff to provide titrated doses at 5- to 10-minute intervals as required. This protocol was shown to be safe, sustainable and effective in changing patterns of analgesia ordering. ${ }^{10-12}$

Ongoing audits showed improvement, but delays to initiation of analgesia remained a concern. This led our group to develop and implement a nurse-initiated opioid analgesia protocol in 2002. The protocol allows specially trained and credentialed nurses to initiate and manage titrated IV opioid analgesia for selected painful conditions, including renal and biliary colic with proven calculi, before the pa- tient is assessed by a doctor. Copies of these protocols and the credentialing process for nurses are available from the authors on request.

The aim of this study was to determine whether patients with renal or biliary colic treated according to this protocol received analgesia earlier than those treated after assessment by a doctor.

\section{Methods}

This retrospective medical record review study was undertaken in the ED of Western Hospital, an urban public teaching hospital located in Melbourne, Australia, with an annual ED census of 32000 patients. The ED is staffed by a mixture of residents and emergency physicians. The study was approved by the institutional research and ethics committee.

Patients treated between Aug. 1, 2002, and Jan. 31, 2003, who had an ED discharge diagnosis of renal or biliary colic (or synonyms, including urinary tract calculus and cholelithiasis) were identified in the ED data management system. Their medical records were reviewed using an explicit data collection tool. Patients under the age of 18 were excluded. Multiple presentations were permitted, but a patient's visit was excluded if no opioid analgesia was administered during that particular visit.

These diagnostic categories were chosen because they 
were diagnoses included in the nurse-initiated analgesia protocol, were readily identifiable from the ED data management system and clinically relevant because they are often associated with severe pain. Suspected limb fracture, the other condition covered by the protocol, was less reliably identifiable from the data management system and therefore cases were likely to be missed, leading to inaccurate results. This group was therefore excluded from this study.

Data collected included age, gender, diagnosis, time of presentation, triage category (using the Australasian Triage Scale [ATS], the revised and renamed former National Triage Scale), ${ }^{13}$ time of first opioid dose, and whether analgesia was doctor- or nurse-initiated. Data collection was carried out by 2 researchers (C. Brumby, A.M.K.). Source documents included ED patient records, patient ED drug charts, ED nursing observation charts and the narcotic drugs register, which was used to cross-check if analgesia was nurse-initiated. Nurse-initiated analgesia was defined as the initiation of analgesia by nursing staff using the nurse-initiated analgesia protocol prior to the patient being seen by a medical officer. This is routinely annotated in the patient's medication chart and in the narcotic drugs register.

The outcome of interest was time to first analgesia, defined as the time of initial opioid administration minus time of presentation. We specified a clinically significant time difference between groups as a difference of more than 10 minutes. This time difference was chosen because the researchers believe that, for patients in severe pain, it represents a meaningful reduction in waiting time.

For the analysis of diagnosis and demographic data, descriptive statistics and chi-squared tests were used. Continuous data (times) were compared using the Mann-Whitney $U$ test for non-parametric data using Analyse-it ${ }^{\mathrm{TM}}$ (Analyse-It Software, Ltd., Leeds, UK). Because a number of patients presented more than once, cluster analysis techniques, stratified by nurse-initiated or not, were employed to minimize multiple presentation effects.

Sample size was calculated based on time to first dose of analgesia using a known value derived from audit data. We aimed to detect a reduction in time to first dose of analgesia from 45 minutes (baseline known from time to analgesia audits) to 30 minutes with $80 \%$ power and an alpha of 0.05 . The estimated standard deviation was 40 minutes. This calculation yielded a target sample of 112 patients per group.

\section{Results}

During the study period, 157 visits by 126 patients met eligibility criteria. Our pre-specified enrolment target was not met because our hospital suspended the nurse-initiated analgesia protocol during the study when an external government body, Melbourne Teaching Hospital's Drug Usage Group, challenged its legality. Figure 1 shows the derivation of the sample. Fifty-eight patients $(37 \%)$ received analgesia via the nurse-initiated analgesia protocol, and 99 (63\%) patients by standard practice (i.e., non-nurse-initiated). Inter-rater reliability for assessment of whether analgesia was nurse-initiated or not was measured on $82 \%$ of records. Kappa analysis yielded a score of 0.92 , indicating very good agreement. Table 1 shows the distribution of gender, age, ATS triage category, ${ }^{13}$ time of presentation, ED diagnosis and disposition between the study groups. Median age was 47 years (range 17-79), and 93 (74\%) patients were men. Baseline characteristics were similar between groups, but there were more presentations of biliary colic in the non-nurse-initiated analgesia group ( $p=0.044$, chi-squared analysis).

The median time to first opioid dose was 31 minutes for the nurse-initiated analgesia group and 57 minutes for the non-nurse-initiated group (effect size, $26 \mathrm{~min}$; 95\% confidence interval $[\mathrm{CI}]$ 16-36 min; $p<0.0001$, Mann-Whitney $U$ test). Cluster analysis showed a slightly larger effect size of 29 minutes (95\% CI 19-41 min; $p<0.0001$ ), and

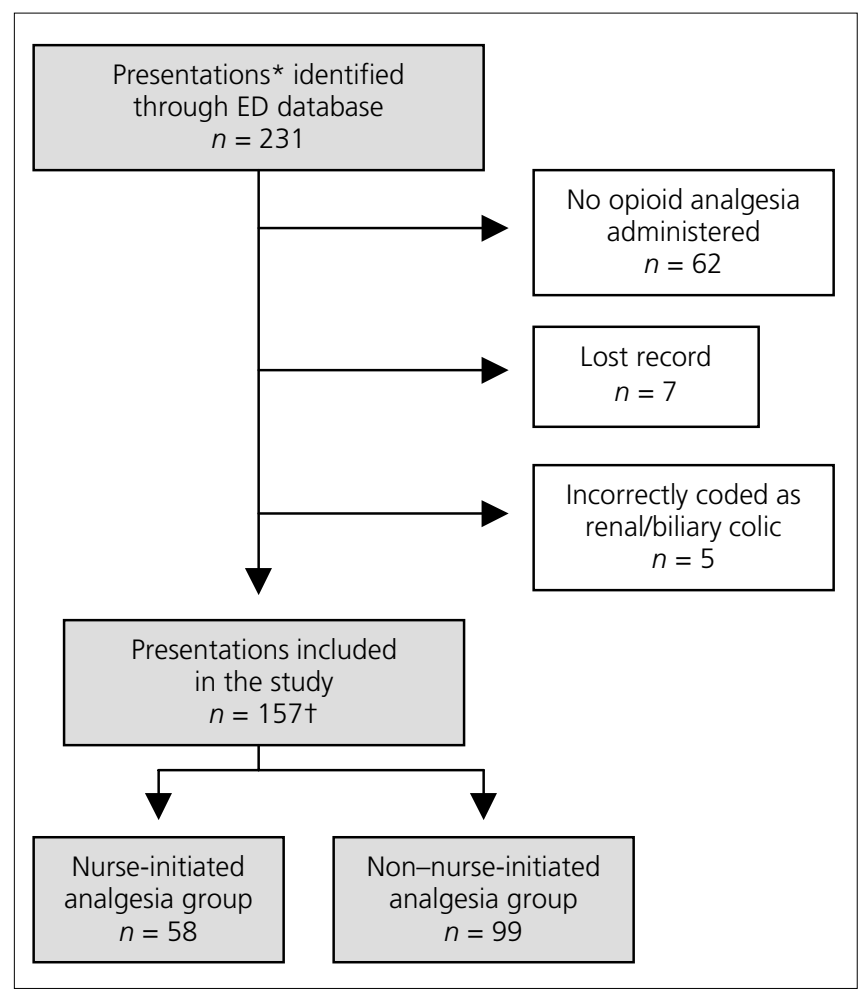

Fig. 1. Derivation of the study sample. *Patients treated in the emergency department (ED) who had a discharge diagnosis of renal or biliary colic. tMultiple presentations were permitted; therefore, 157 ED visits (126 patients) were included in the study. 
subgroup analysis by diagnostic group showed significant reductions in time to first dose of analgesia in both groups (Table 2). There were no documented cases of respiratory depression (95\% CI 0.0\%-4.0\%).

\section{Discussion}

One of the primary goals of emergency medicine is the prompt, effective alleviation of pain. Relief of pain is increasingly being viewed as a basic human right, and thus an ethical as well as a clinical concern for health professionals. ${ }^{14}$ Despite this, international research shows pain to be inadequately managed within the acute setting. ${ }^{1-6}$ One approach to improving pain management has been the development of analgesia protocols. The scope of these protocols includes centralization of the nursing role, and po- tential interventions range from first aid measures, such as limb elevation and ice application, ${ }^{15}$ to nurse-initiated opioids..$^{15,16}$

This study shows that, in our setting, nurse-initiated opioid analgesia reduced time to first analgesic dose by approximately 25 minutes. No serious adverse effects were found, and this is consistent with previous reports. ${ }^{12}$ Our findings agree with those reported by Fry and Holdgate, ${ }^{16}$ who investigated the impact of nurse-initiated IV opioids on time to first dose of analgesia by evaluating a prospective convenience sample of 349 patients over a 12-month period. Unlike the present study, all patients received nurse-initiated analgesia and the impact on time to first dose was evaluated by comparing time to first analgesic and time to be seen by a doctor, on the assumption that the latter was the earliest time that analgesia could have been

\section{Table 1. Comparison of study cohorts}

\begin{tabular}{|c|c|c|c|c|}
\hline \multirow[b]{2}{*}{ Variable } & \multicolumn{2}{|c|}{$\begin{array}{c}\text { Analgesia group; } \\
\text { no. (and \%) of presentations* }\end{array}$} & \multirow[b]{2}{*}{$\begin{array}{l}\text { No. of charts with } \\
\text { complete data }\end{array}$} & \multirow[b]{2}{*}{$p$ value } \\
\hline & $\begin{array}{l}\text { Nurse-initiated } \\
\quad n=58\end{array}$ & $\begin{array}{c}\text { Non-nurse-initiated } \\
n=99\end{array}$ & & \\
\hline Male gendert & 37 / 49 (76) & $56 / 77(73)$ & $126 / 157(80)$ & 0.88 \\
\hline Median age, yrt & 44 & 50 & & 0.05 \\
\hline Triage category $\ddagger$ & & & $156 / 157$ (99) & 0.14 \\
\hline ATS 2 & $9(16)$ & $8(8)$ & 17 & \\
\hline ATS 3 & $42(72)$ & $69(70)$ & 110 & \\
\hline ATS 4 & $7(12)$ & $22(22)$ & 29 & \\
\hline Time of presentation & & & $157 / 157(100)$ & 0.41 \\
\hline Day (0800-1600) & $16(28)$ & $37(37)$ & $53(34)$ & \\
\hline Evening (1600-2200) & $15(26)$ & $25(26)$ & $40(25)$ & \\
\hline Night (2200-0800) & $27(46)$ & 37 (37) & $64(41)$ & \\
\hline ED diagnosis & & & $157 / 157(100)$ & 0.04 \\
\hline Renal colic & $50(86)$ & $70(71)$ & $120(76)$ & \\
\hline Bilary colic & $8(14)$ & $29(29)$ & $37(24)$ & \\
\hline Disposition & & & 155 / 157 (99) & 0.12 \\
\hline Admitted & $9(16)$ & $27(28) \S$ & 36 & \\
\hline Discharged & $49(84)$ & $70(72) \S$ & 119 & \\
\hline \multicolumn{5}{|c|}{$\begin{array}{l}\text { *Multiple presentations were permitted; therefore, } 157 \text { ED presentations (126 patients) were included in the study. } \\
\text { tBased on } 126 \text { patients. } \\
\text { ‡Australasian Triage Scale (ATS) } \\
\text { §Two cases missing data. }\end{array}$} \\
\hline
\end{tabular}

Table 2. Comparison of median times to analgesia

\begin{tabular}{lccccc} 
& \multicolumn{2}{c}{$\begin{array}{c}\text { Analgesia group; } \\
\text { Group }\end{array}$} & $\begin{array}{l}\text { median time to analgesia, min } \\
\text { Nurse-initiated }\end{array}$ & $\begin{array}{c}\text { Non-nurse-initiated } \\
\text { Effect size, } \\
\text { min (and 95\% Cl) }\end{array}$ & $p$ value \\
\hline Overall & 31 & 57 & $26(16-36)$ & $<0.0001$ \\
Clustered & 31 & 60 & $29(19-41)$ & $<0.0001$ \\
Renal colic & 29 & 50 & $21(12-32)$ & $<0.0001$ \\
Biliary colic & 32 & 66 & $34(8-104)$ & 0.0174 \\
\hline
\end{tabular}


ordered under a physician-initiated system. Fry and Holdgate found that the median time to first-dose analgesia for patients receiving nurse-initiated opioids was 18 minutes, and that median time to doctor was 52 minutes. The median difference between time to first dose analgesia and time to be seen by a doctor was 26 minutes. It is not clear, however, what proportion of patients was treated by the nurse-initiated protocol or what treatment was received by those not treated according to the protocol.

Pain management protocols have been implemented in Australia and internationally with positive results. ${ }^{10,11,16-18}$ Despite these findings, a number of concerns have been raised, relating to implementation, utilization and compliance, sustainability of practice, and effectiveness in improving patient outcomes. ${ }^{12}$ In particular, the safety of opioid analgesia protocols has been questioned because of the potential for respiratory depression and cardiovascular instability. Yet the absence of major adverse events in our study concurs with the findings of 2 larger studies of nurse-managed IV opiates. ${ }^{12,16}$

Although the evidence suggests that nurse-initiated analgesia facilitates earlier administration of opioids, some clinicians may be concerned that analgesia before medical assessment might reduce clinical diagnostic accuracy. For these reasons, and to assure safety, our protocol is limited to patients under 60 years with known biliary or renal calculus disease, normal vital signs and classical symptoms the same as they have previously experienced. Further, there is a growing body of evidence that prompt analgesia does not adversely impact physical signs or diagnostic accuracy for patients with abdominal pain. ${ }^{19-21}$ Consequently, we believe these concerns should not be a barrier to the provision of analgesia for patients with abdominal pain.

During this study, the Melbourne Teaching Hospital's Drug Usage Group challenged the legality of nurse-initiated analgesia and the protocol was suspended. Concerns focused on whether this protocol represented drug "prescription" by nurses or standing orders initiated by physicians. We expect this and previous work to prompt changes in the way opioid protocols are interpreted and applied. These would enable us to recommence nurse-initiated opioids in the near future. Such issues are not limited to the State of Victoria. Within the United Kingdom, the British Medicines Act of 1968 states that prescription medication should be administered under the direction of a doctor, but does not specify what direction is necessary. ${ }^{15}$ A common interpretation within the UK is that physician-initiated protocols are sufficient. ${ }^{22}$ Restricted medications, including opioids, have been administered under group protocols involving nurses, but the legality of this practice has yet to be tested. ${ }^{22}$

\section{Limitations}

Documentation errors and omissions are common in any retrospective study, but these would be unlikely to bias our primary outcome. Although inter-rater reliability was high for the data tested, subjectivity of case note interpretation may have impacted results. The process change itself may have contributed to reduced times in the nurse-initiated group due to a "honeymoon" type enthusiasm. We consider this to be unlikely, however, because the protocol was an extension of a pre-existing nurse-managed opioid analgesia protocol implemented in 1995; the present study occurred one-year post-implementation, and no specific promotional activities for the study or the protocol occurred. The cohorts studied were not randomized, rather defined post hoc by treatment received. This may have been impacted by the availability of credentialed nurses to administer the nurse-initiated protocol. The groups differed in distribution of diagnostic groups for reasons that are unclear, which may have influenced results. There was a trend toward the nurse-initiated group having higher triage categories, which may reflect a perception that these patients were in greater pain. Because pain score data were not collected, this cannot be tested.

The study was concluded prematurely due to suspension of the protocol by the hospital on the advice of an external body, before the calculated sample size was attained. An earlier initiation of analgesia does not of necessity translate into earlier pain control; however, the review and titration process inherent in the protocols studied makes that likely. Generalizability of this or similar protocols cannot be assumed. Factors such as training and seniority of nursing staff, ED size and overall staff and patients numbers and local operational, legal and political issues will determine safety, appropriateness and impact.

\section{Conclusions}

In summary, this study has demonstrated that implementation of a nurse-initiated analgesia protocol has the potential to reduce time to first dose of analgesia for patients presenting to an ED with renal and biliary colic. Further studies to confirm this and efforts to overcome legal barriers to nurse initiation of analgesia are needed.

Acknowledgements: We acknowledge the work of Denise Green, Clinical Nurse Consultant and Nurse Educator, for developing the training and competency packages and facilitating the development of the protocols that underpin this research. We thank the staff of the Emergency Department for their enthusiasm for analgesia in a very busy department, in particular Dianne Dixon, Nurse Unit Manage,r and Matt Kropman, RN. We also thank Debra Kerr for her constructive comments on the manuscript. 
Competing interests: None declared.

\section{References}

1. Blau WS, Dalton JA, Lindley C. Organisation of hospital-based acute pain management programs. South Med J 1999;92:465-71.

2. Wilson JE, Pendleton JM. Oligoanalgesia in the emergency department. Am J Emerg Med 1989;7:620-3.

3. Selbst SM, Clark M. Analgesic use in the emergency department. Ann Emerg Med 1990;19:1010-3.

4. Reich M. Bodiwala GG. Use of analgesia in severe pain in the accident and emergency department. Arch Emerg Med 1987;4:25-31.

5. Lewis LM, Lasater LC, Brooks CB. Are emergency physicians too stingy with analgesics? South Med J 1994;87:7-9.

6. Ducharme J, Barber C. A prospective blinded study on emergency pain assessment and therapy. J Emerg Med 1995;13:571-5.

7. Barletta JF, Erstad BL, Loew M, Keim SM. A prospective study of pain control in the emergency department. Am J Ther 2000;7: 251-5.

8. Ducharme J. Proceedings from the First International Symposium on Pain Research in Emergency Departments. Ann Emerg Med. 1996;27:399-403.

9. Liebelt E, Levick N. Acute pain management, analgesia and anxiolysis in the adult patient. In: Emergency medicine. A comprehensive study guide. 5th ed. New York: McGraw-Hill; 1999.

10. Kelly AM. A process approach to improving pain management in the emergency department: development and evaluation. J Accid Emerg Med 2000;17:185-7.

11. Kelly AM. Nurse-managed analgesia for renal colic pain in the emergency department. Aust Health Rev 2000;23:185-9.

12. Coman M, Kelly AM. Safety of a nurse-managed, titrated analgesia protocol for the management of severe pain in the emergency department. Emerg Med (Fremantle) 1999;11:128-31.
13. Australasian College for Emergency Medicine. Guidelines for Implementation of the Australasian Triage Scale in Emergency Medicine. Nov 2000. Available: www.acem.org.au/open/documents /triageguide.htm (revised National Triage Scale; formulated and adopted by the College 2000 Nov; accessed 2005 Apr 7).

14. Woolf SH. Practice guidelines: a new reality in medicine. III. Impact on patient care. Arch Intern Med 1993;153(23):2646-55.

15. Larsen D. An investigation into the assessment and management of pain by triage nurses in greater London $\mathrm{A} \& \mathrm{E}$ departments. Emerg Nurs 2000;8:18-24.

16. Fry M, Holdgate A. Nurse-initiated intravenous morphine in the emergency department: efficacy, rate of adverse events and impact on time to analgesia. Emerg Med (Fremantle) 2002;14:249-54.

17. Zohar Z, Eitan A, Halperin P, Stolero J, Hadid S, Shemer J, et al. Pain relief in major trauma patients: an Israeli perspective. J Trauma 2001;51:767-72.

18. Goodacre SW, Roden RK. A protocol to improve analgesia use in the accident and emergency department. J Accid Emerg Med 1996;13:177-9.

19. Thomas SH, Silen W, Cheema F, Reisner A, Aman S, Goldstein $\mathrm{JN}$, et al. Effects of morphine analgesia on diagnostic accuracy in emergency department patients with abdominal pain: a prospective, randomised trial. J Am Coll Surg 2003;196:18-31.

20. LoVecchio F, Oster N, Sturmann K, Nelson LS, Flashner S, Finger R. The use of analgesics in patients with abdominal pain. J Emerg Med 1997;15:775-9.

21. Pace S, Burke TF. Intravenous morphine for early pain relief in patients with acute abdominal pain. Acad Emerg Med 1996;3: 1086-92.

22. Jones M, Gough P. Nurse prescribing - Why has it taken so long? Nurs Stand 1997;11(20):39- 42.

Correspondence to: Professor Anne-Maree Kelly, Department of Emergency Medicine, Western Hospital, Private Bag, Footscray 3011, Melbourne, Victoria, Australia; +613 8345 6315, fax +613 9318 4790, AnneMaree.Kelly@wh.org.au 